\title{
EFFECT OF ANNEALING ON HOT BAND TEXTURE OF FERRITIC STAINLESS STEEL
}

\author{
C. D. SINGH \\ Research and Development Centre for Iron and Steel, \\ Steel Authority of India Limited, Ranchi-834002, India
}

(Received 30 October 1995)

\begin{abstract}
The textural and microstructural banding through the thickness of $17 \% \mathrm{Cr}$ ferritic stainless steel hot band has been investigated. The surface texture is nearly random and consists of shear texture components formed by simultaneous action of shear deformation and dynamic recrystallisation. The texture in the central layer is a strong recrystallisation-type. The through-thickness textural and microstructural banding, to a large extent, has been weakened by annealing the hot band in two-phase $(\alpha+\gamma)$ region, as opposed to single-phase $(\alpha)$ annealing.
\end{abstract}

KEY WORDS: Banding, ferrite, martensite, austenite, shear texture, recrystallisation texture.

\section{INTRODUCTION}

In the past, many investigations related to the evolution of hot rolling texture (Harase et al., 1990; Hölscher, Raabe and Lücke, 1991; Raabe and Lücke, 1992), hot band annealing texture (Hölscher and Staubwasser, 1993) and of cold rolling and annealing textures (Lewis and Pickering, 1983; Vlad et al., 1988; Hölscher, Raabe and Lücke, 1991) have been carried out in $17 \% \mathrm{Cr}$ ferritic stainless steel. This steel is in large demand and finding its uses in many industrial, domestic and architectural appliances, mainly, because of its relatively lower cost, good corrosion resistance and esthetically pleasing appearance. The normal process of producing the steel strips consists of continuously casting into slabs, hot rolling the slabs into strips, batch annealing the hot bands (HB) in the box furnaces at the temperature $(\sim 1123 \mathrm{~K})$ for a total period of 50 hours (soaking time: 5 hours), pickling the annealed hot bands (AHB), cold rolling to final gauges in single or double stages and finally annealing and then pickling before being skin-passed as finished products. Of all the processes involved in the commercial production of the strips, the batch annealing process of the HB is the most time and energy consuming and hence the main bottle neck in meeting the fast growing market demand. However, the steel strips so produced suffer from low drawability and high roping, both of which are totally dependent upon the texture present in the strips and thus require optimisation of texture components at each level of processing, particularly at the HB annealing stage, for their improvement.

It is well known fact that the roping phenomenon occurs in the formed steel components and produces unesthetical surface. It is beyond doubt that this roping is the result of anisotropic flow of mixed textures, and that the origin of these textures may be traced to textural and microstructural banding during hot rolling. Based on crystal plasticity arguments and pole figures, Chao (1967) first showed that severe 
roping will occur when a texture mix, in the form of alternating bands of cube-onface component $\{001\}\langle 110\rangle$ embedded in a cube-on-corner matrix texture $\{111\}\langle 110\rangle$, is present in a material. Later, Wright (1972) used a plastic buckling model to account the observed roping morphology. Independently, Takechi et al. (1967) showed alternating bands of grains with $\{111\}<110\rangle$ or $\{112\}<110>$ orientations would develop an undulating cross-section with strain in $\langle 110\rangle$ direction. Thus, the grain by grain deformation processes causing roping seem to be controversial. However, it is an ample clear that the elimination of the textural and microstructural banding is an essential requirement for alleviating the roping phenomenon. Methods to reduce the textural and microstructural band in commercial ferritic stainless steels have been effected by modifying the alloy chemistry (Davison, 1974; 1975; Yamada and Tokunaga, 1985; Sawatani et al., 1985), the casting practice (Viallon and Heretier, 1977; Itoh et al., 1982; Tashiro et al., 1982) and the thermo-mechanical processing (Waxweiler, 1962; Chalk, 1969; Harase, Kamano and Ueno, 1983; Harase, Heno and Nagaie, 1983). While the first two methods invoke the elimination of austenite phase and the enhancement of equiaxed grain ratio during processing respectively, the latter one utilises faster recrystallisation processes (i.e. both dynamic and static) to reduce the banding. This dynamic recrystallisation process gets affected by the accompanying $\alpha \leftrightarrows \gamma$ partial transformation during hot rolling of $17 \% \mathrm{Cr}$ ferritic stainless steel. The role of this partial transformation on the development of hot band texture and microstructure is, clearly, not known. Further, one of the most effective ways of controlling roping behaviour involves the cold rolling of ferrite containing austenitederived ferrite and/or austenite derived decomposed martensite, which is yet untapped and obtained by high temperature quick annealing of the HB in two-phase $(\alpha+\gamma)$ region. This two-phase annealing has some industrial importance towards the development of continuous annealing technology of the $\mathrm{HB}$ in the continuous annealing furnace.

It is with the intention of eliminating the textural and microstructural banding present in the HB by two-phase $(\alpha+\gamma)$ annealing, as opposed to single-phase $(\alpha)$ annealing, and also of the development of continuous annealing process parameters that a comprehensive analysis by orientation distribution functions (ODF) technique has been used to study the original texture in the hot band and subsequent changes upon annealing. The rolling, transverse and normal directions of the strip are denoted by $\mathrm{RD}, \mathrm{TD}$ and $\mathrm{ND}$ respectively.

\section{EXPERIMENTAL PROCEDURE}

The commercially produced $5.50 \mathrm{~mm}$ thick hot band (HB) of nominal chemical composition (by wt\%) : $0.041 \% \mathrm{C}, 0.31 \% \mathrm{Si}, 0.41 \% \mathrm{Mn}, 0.001 \% \mathrm{~S}, 0.022 \% \mathrm{P}, 0.029 \% \mathrm{~N}$, $16.73 \% \mathrm{Cr}, 0.24 \% \mathrm{Ni}$ was used for the present investigation. As per supplier's information, the reheating temperature of the slabs and the finishing temperature of the hot rolled coils were about $1453 \mathrm{~K}$ and $1223 \mathrm{~K}$ respectively. The HB strips were annealed in the single-phase $(\alpha)$ region at a temperature $1123 \mathrm{~K}$ for 5 hours and then furnace cooled to simulate the batch annealing in box furnaces. Furthermore, the continuous annealing process of the $\mathrm{HB}$ was simulated by annealing the strips in the two-phase $(\alpha+\gamma)$ region at $1223 \mathrm{~K}$ for 5 minutes and cooling in air. The HB and these annealed hot bands (AHB) were pickled in pickling solution (by volume \%) of $10 \% \mathrm{HNO}_{3}+4 \% \mathrm{HF}+86 \%$ distilled water at a temperature of $323 \mathrm{~K}$ for a period of 5 minutes for removal of any oxides and scales on their surfaces. 
Microstructural examinations were conducted by optical microscopy on specimens of $\mathrm{HB}$ and AHBs mechanically polished and chemically etched in modified Villela's solution of saturated picral containing $10 \% \mathrm{HCl}$ and $2 \% \mathrm{HNO}_{3}$ at sections $(\mathrm{S}=1, \mathrm{~S}=0)$ cut perpendicular to transverse direction (i.e. longitudinal section). Here $S=1$ and $S=0$ represent surface and centre of the specimen, respectively. The hardness of ferrite $(\alpha)$ region and martensite $\left(\alpha^{\prime}\right)$ or tempered martensite region was measured for $S=1$ and $S=0$ levels of the longitudinal section using micro-Vickers hardness tester (load: $25 \mathrm{P}$ ).

$\mathrm{X}$-ray texture measurements were performed for $\mathrm{HB}$ and AHBs materials at the sections ( $S=1$ and $S=0$ levels) parallel to the rolling plane on an automatic texture goniometer, using $\mathrm{Mo}_{\mathrm{K} \alpha}$ radiation. For each ground and etched specimen $(20 \mathrm{~mm} \times$ $14 \mathrm{~mm})$, the texture was determined by measuring four incomplete pole-figures of the planes $\{110\},\{200\},\{112\}$ and $\{103\}$, using back reflection technique (Schulz, 1949). For each measurement, the diffracted intensity was recorded continuously every $5^{\circ}$ along concentric circles in the angular range from 0 to $75^{\circ}$ in steps of $5^{\circ}$ and subjected to background, geometrical and defocussing corrections using a random specimen of pressed and sintered iron powders. The three dimensional ODF was calculated from the data of four incomplete pole-figures following the series expansion method (Bunge, 1982) and using the pseudo-normalisation technique (Kern and Bergmann, 1978). The series was extended upto $1=22$ using even terms only. In each case, the texture index, $\mathrm{J}$, measured as a mean square deviation of the ODF from random distribution was also determined.

Due to cubic crystal and othorhombic sample symmetry, a general orientation possesses 96 symmetrical equivalent positions in Euler angular space. The Euler space $\left(0^{\circ} \leq \phi_{1}, \phi, \phi_{2} \leq 90^{\circ}\right)$ used in the present investigation contained each orientation three times each in three basic ranges. The measured ODF $\mathrm{f}(\mathrm{g})$ was presented in the form of isotensity contour lines corresponding to multiples of random orientation density in section $\phi_{1}$ or $\phi_{2}=$ constant $\left(0^{\circ}, 5^{\circ}, 10^{\circ}, \ldots 90^{\circ}\right)$ through this Euler angle space. Although the ODFs, which will be discussed contain ghost errors (Matthies, 1979; Lücke et al., 1981), they are sufficiently small so as not to affect the interpretation of the principal results.

\section{EXPERIMENTAL RESULTS}

\subsection{Microstructure Evolution}

Figure 1(a) and (b) shows the microstructures of the longitudinal sections near the surface $(S=1)$ and the centre $(S=0)$ levels of the $H B$, respectively. The most interesting feature of these microstructures is the presence of through-thickness bands of ferrite $(\alpha)$ and martensite $\left(\alpha^{\prime}\right)$ along RD. Here, the bright-etching bands are ferrite and the dark-etching bands are martensite. The formation of martensite occurs as a result of partial martensitic transformation of austenite $\left(\gamma \rightarrow \alpha^{\prime}\right)$, where austenite $(\gamma)$ transforms to martensite $\left(\alpha^{\prime}\right)$ upon cooling form hot rolling. Precipitation of carbides (presumably $\mathrm{M}_{23} \mathrm{C}_{6}$ ), predominantly, within ferrite bands is clearly evident in these microstructures. However, the carbides formed near the central level of the HB are relatively finer. The contrast in the above micrographs also reveals that the untransformed ferrite bands are comparatively coarser and these bands show an early stage of recrystallisation as manifested by elongated recrystallised grains, often 
a

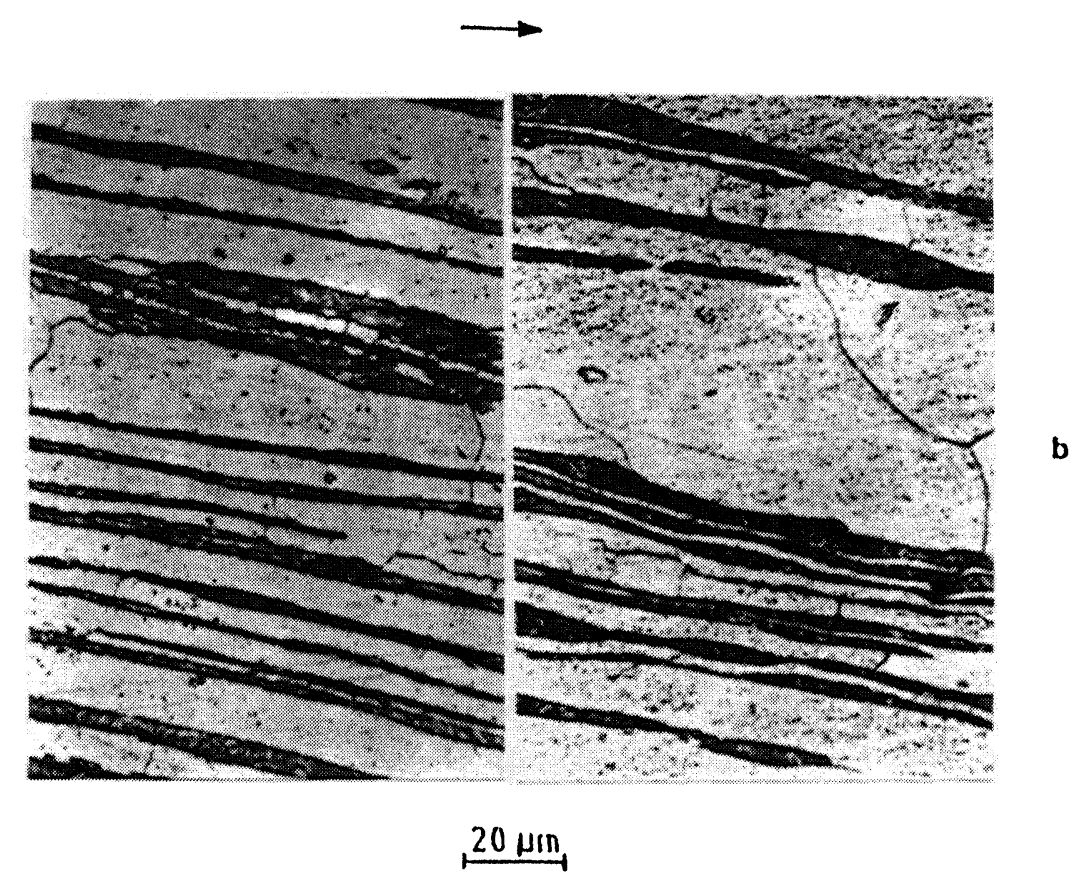

Figure 1 Optical micrographs of longitudinal sections of hot band: (a) near surface $(S=1)$ (b) at centre $(S=0)$. Arrow parallel to $R D$.

associated with prior $\alpha-\gamma$ boundaries. Furthermore, it is surprising to note that very fine ferrite grains mostly associated with $\gamma-\gamma$ boundaries and also forming within recrystallised austenite bands, before the onset of martensite transformation, are other landmark of these microstructures. The average volume fraction of martensite measured through the thickness of the HB was about $25 \%$. The measured hardness values of ferrite and martensite bands near the surface were about $206 \mathrm{HV}$ and $322 \mathrm{HV}$, respectively, while those at the central layer were about $193 \mathrm{HV}$ and $322 \mathrm{HV}$.

The microstructures of the longitudinal sections at the surface $(S=1)$ and the central $(S=0)$ layers of the simulated batch annealed hot band (AHB) are given in Figure 2 (a) and (b), respectively. Ferrite and carbide are the constituents of these microstructures. During single-phase annealing, the martensite bands have decomposed into aggregates of ferrite and carbide. Further, the martensite-derived ferrite is subjected to recrystallisation process and grain growth of such ferrite has taken place because of the coarsening of carbides. Significantly, the prior ferrite-austenite as well as the ferrite-ferrite boundaries are the potential nucleation sites for carbide precipitation. Additionally, the precipitation of carbides within the ferrite bands is more at the central layers than that near the surface and sub-surface layers. The figure also depicts that some ferrite grains, generally, associated with prior ferriteaustenite boundaries, have migrated and grown across the original ferrite bands but still the through-thickness banding exists. Since all grain boundaries are heavily pinned up by the carbides, the through-thickness banding of ferrite grains persists. These carbides are relatively coarser than those obtained in the $\mathrm{HB}$ after hot rolling. The hardness values of ferrite and decomposed martensite near the surface layers 


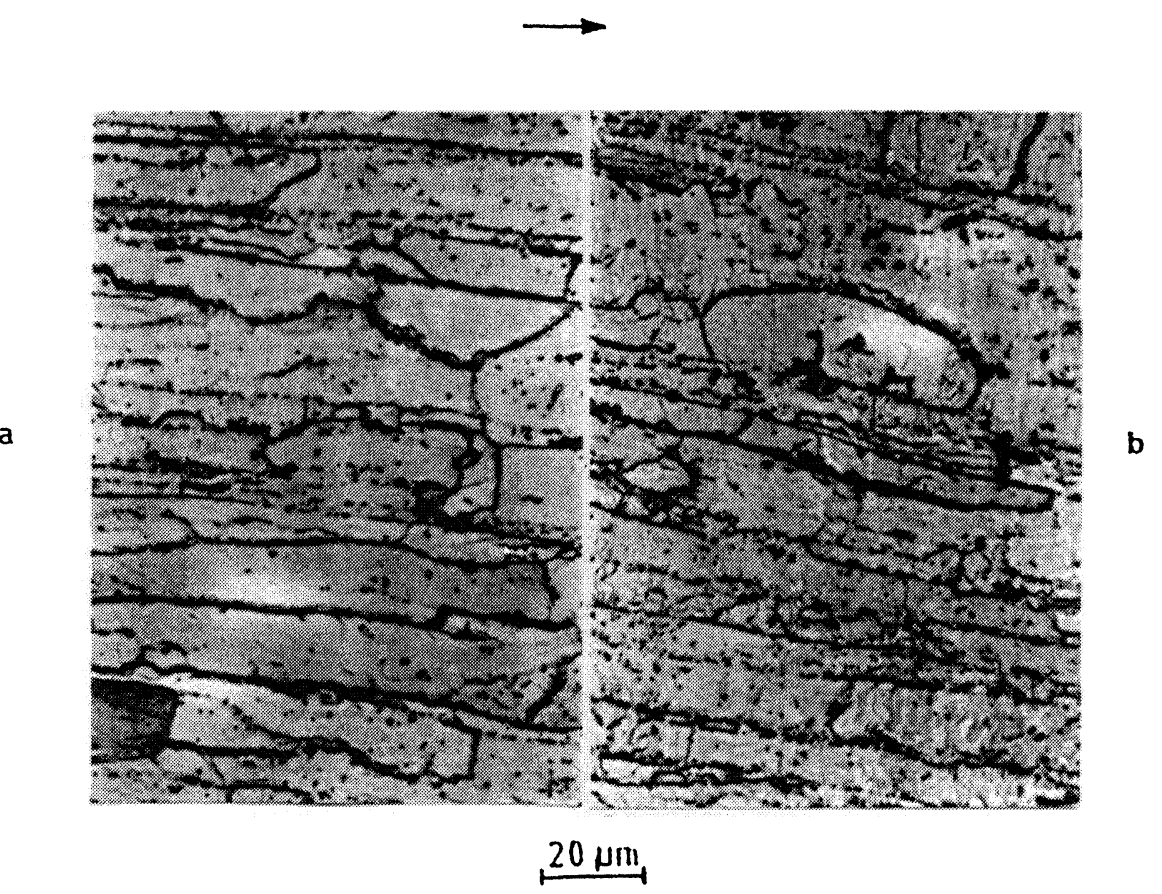

Figure 2 Optical micrographs of longitudinal sections of single-phase annealed hot band: (a) near surface $(S=1)(b)$ at centre $(S=0)$. Arrow parallel to $R D$.

were about $206 \mathrm{HV}$ and $295 \mathrm{HV}$ respectively whereas the hardness values of these phases at the central layers were about $234 \mathrm{HV}$ and $274 \mathrm{HV}$.

On the contrary, Figure 3 (a) and (b) denotes the microstructures of the longitudinal sections near the surface $(S=1)$ and the central $(S=0)$ layers of the simulated continuous annealed hot band (AHB). During the given high temperature quick annealing in the two-phase $(\alpha+\gamma)$ region, few ferrite grains, commonly associated with prior ferrite-austenite boundaries, and the austenite-derived ferrite grains have grown in the original ferrite bands and the decomposed martensite bands, respectively. Here, the original martensite bands have just decomposed into aggregates of ferrite and carbide. The martensite-derived ferrite has also just recrystallised. On the other hand, some austenite, obtained as a result of this two-phase annealing, has transformed into ferrite partially before transforming into martensite upon cooling. This martensite is very small in amount $(\leq 3 \%)$ and often associated with the ferrite band boundaries. Some of this martensite has also decomposed in ferrite-carbide aggregates. In addition to the above microstructural features, precipitation of carbides has occurred, predominantly, on the prior ferrite-austenite and ferrite-ferrite boundaries. There is also a copious carbide precipitation within the ferrite bands. In contrast to single-phase annealing, the through-thickness structural banding has decreased to a greater extent. The measured hardness values of ferrite and just decomposed martensite near the surface layers were about $184 \mathrm{HV}$ and $221 \mathrm{HV}$, respectively, and those at the central layers were about $181 \mathrm{HV}$ and $297 \mathrm{HV}$. 


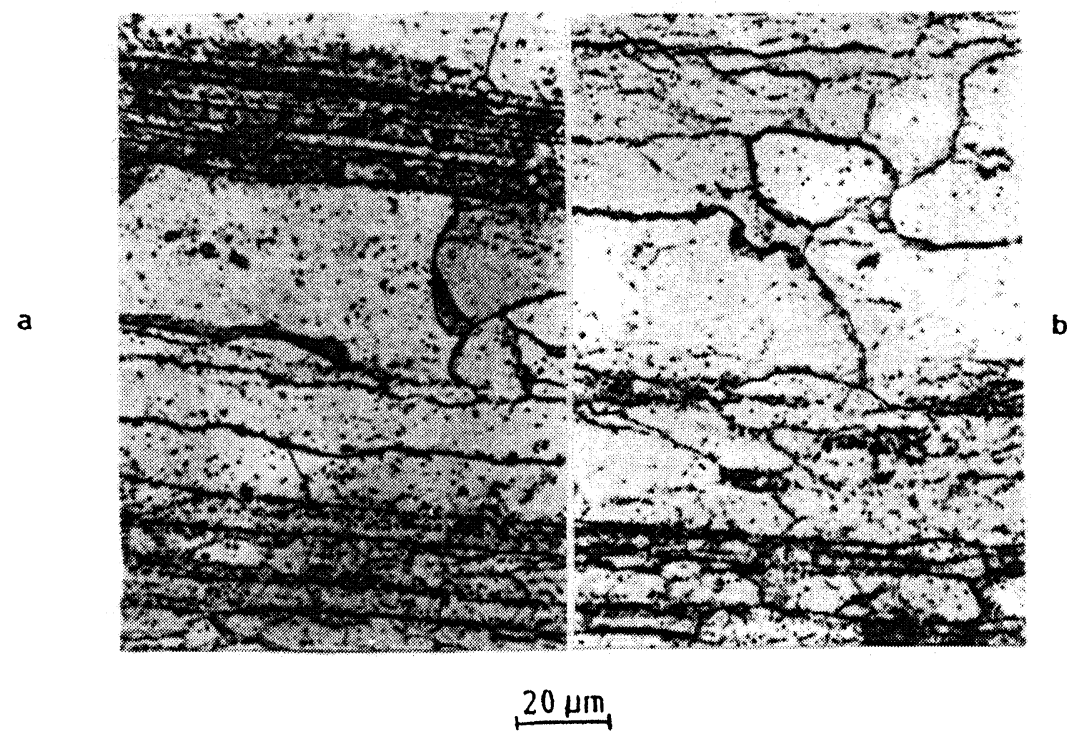

Figure 3 Optical micrographs of longitudinal sections of two-phase annealed hot band: (a) near surface $(S=1)(b)$ at centre $(S=0)$. Arrow parallel to $R D$.

\subsection{Texture Evolution}

The ODFs of crystallites near the surface layer $(S=1)$ of the $\mathrm{HB}$, single-phase and twophase annealed AHBs in constant $\phi_{2}$ sections are shown in Figures 4,5 and 6, respectively. These ODFs exhibit maxima of orientations $\{011\}<100\rangle, \approx\{123\}<634>$ and $\{112\}<111>$, which are major components of the surface texture. The other minor orientations are $\left.\left.\left\{\begin{array}{lll}0 & 3 & 11\end{array}\right\}<100>,\{011\}<113\right\rangle,\{011\}<112\right\rangle$ and $\left.\{001\}<100\right\rangle$. It is clear from these ODFs results that the surface texture can be best described by three limited tubes of preferred orientations in the Euler space. The first tube has its $<110>$ fibre axis parallel to ND $(<110>/ N D)$ and it stretches from $\{011\}<100>$ to $\approx\{011]<112>$. The second orientation tube, with its fibre axis $<110>$ inclined about $60^{\circ}$ from $\mathrm{ND}$ towards $\mathrm{RD}\left(<110>60^{\circ} \mathrm{ND}\right)$, runs from $\{112\}<111>$ through $\approx\{123\}<634>$ to $\approx\{011\}<112>$. The third orientation tube has its $<100>$ fibre axis parallel to $\mathrm{RD}(<100>/ / \mathrm{RD})$ and it extends from $\{011\}<100>$ to $\{001\}<100>$. The orientation density plots along these limited fibres (i.e. $<110>/ \mathbb{N D},<110>60^{\circ} \mathrm{ND}$ and $<100>/ / R D)$ are given in Figure 7,8 and 9 , respectively. It is evident from Figure 7 that the texture profile along $<110>/$ ND fibre contains a strong peak at $\{011\}<100>$ and a concealed peak at $\{011\}<113\rangle$, which is about $10^{\circ}$ away from the ideal orientation $\{011\}<112>$ rotated about ND. Similarly, the texture profile of $<110>60^{\circ} \mathrm{ND}$ fibre (Figure 8) reveals a strong peak near $\{123\}<634>$ and two minor peaks at $\{112\}<111>$ and $\{011\}<112>$, whereas that of $<100>/ /$ RD fibre (Figure 9) depicts a strong peak at $\{011\}<100>$ and a concealed peak at $\left\{\begin{array}{lll}0 & 311\}<100>\text {. The }\end{array}\right.$ orientation $\left\{\begin{array}{lll}0 & 3 & 11\end{array}\right\}<100>$ is $15^{\circ}$ away from the ideal orientation $\{001\}<100>$ rotated about RD. Furthermore, the values of the texture index near the surface layer of the $\mathrm{HB}$, single-phase and two-phase annealed AHBs are 1.56, 5.10 and 1.83, respectively. 

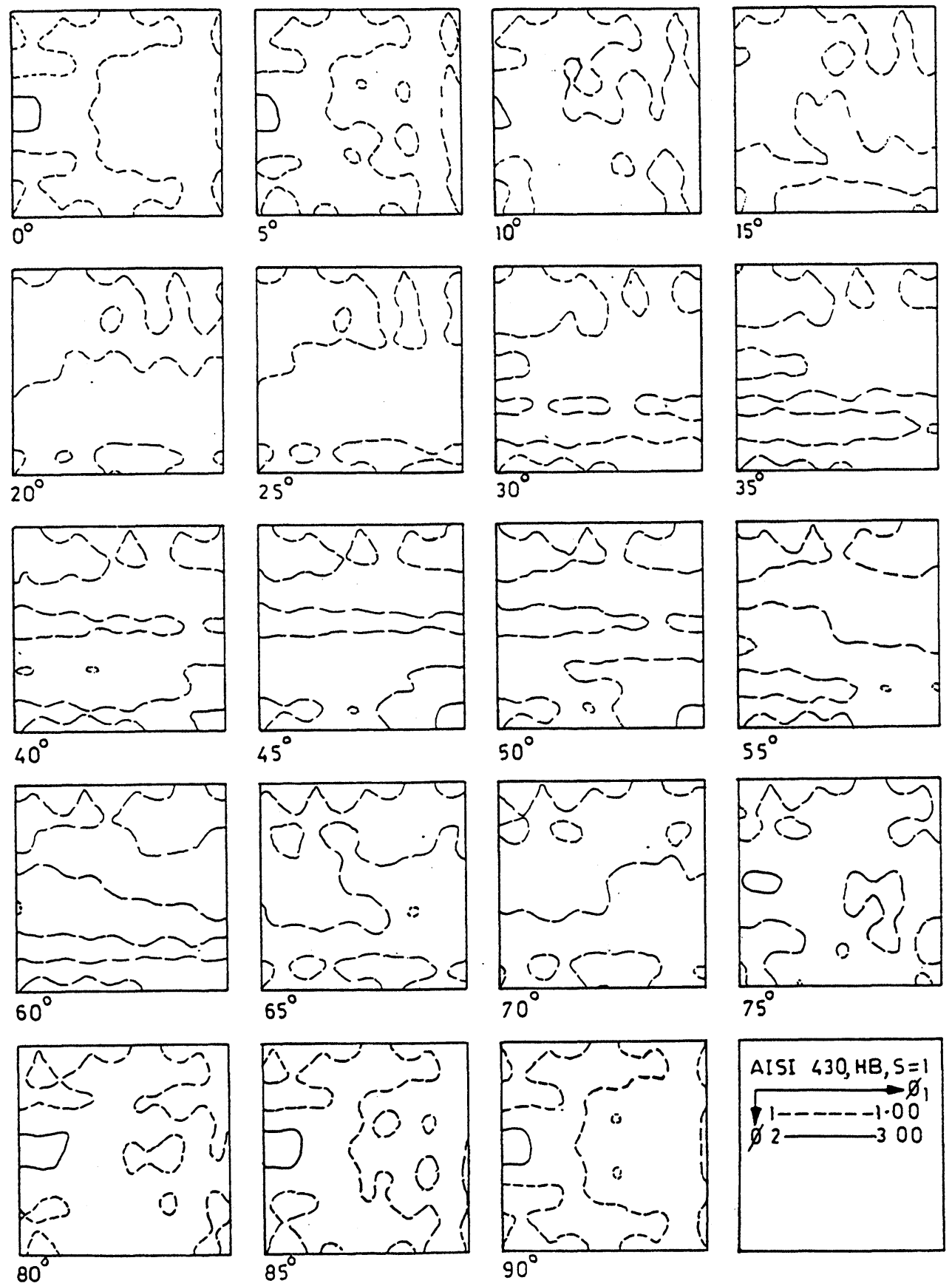

Figure 4 ODF for surface $(S=1)$ level of hot band in constant $\phi_{2}$ sections. 

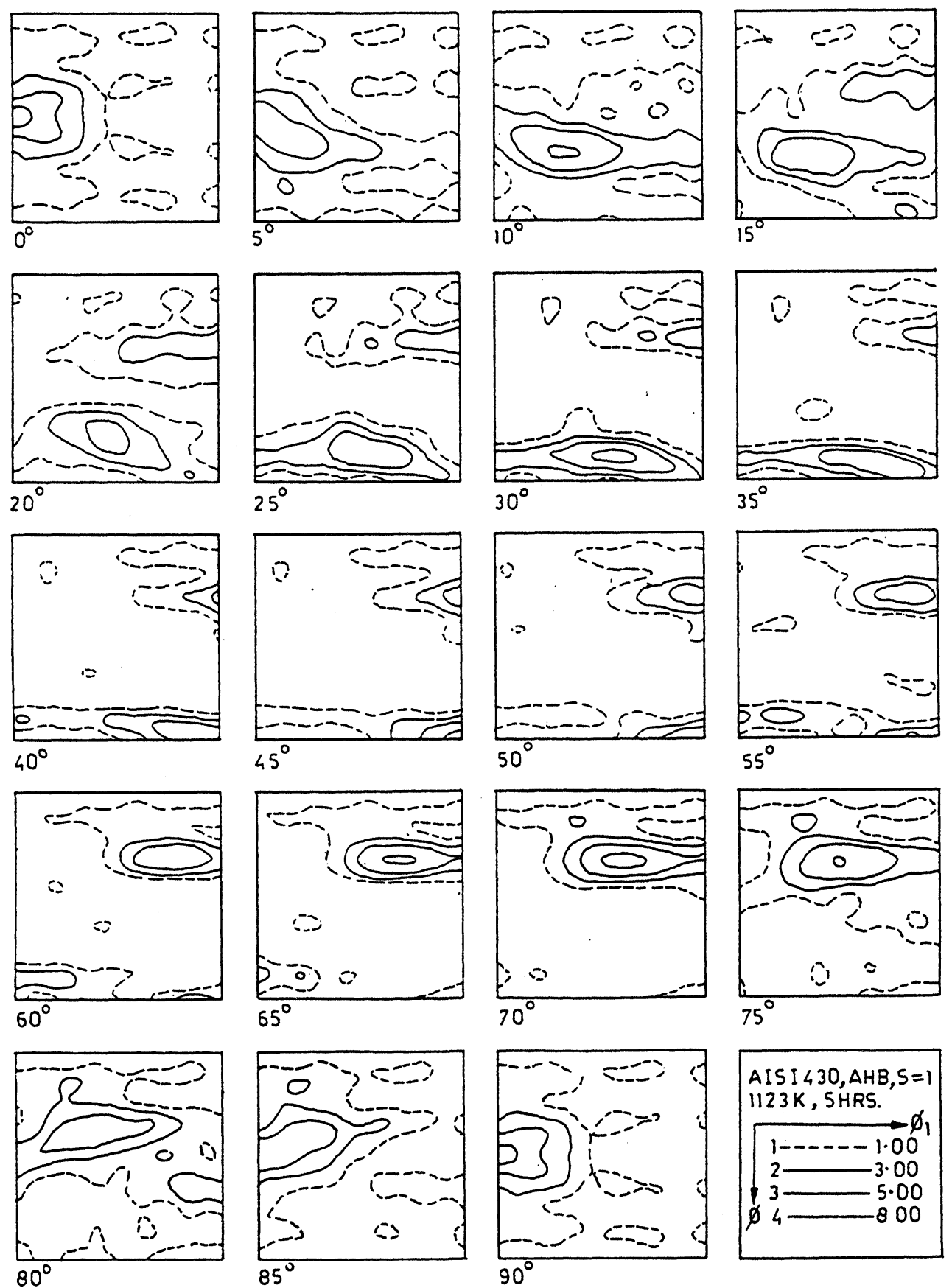

Figure 5 ODF for surface $(S=1)$ level of single-phase annealed hot band in constant $\phi_{2}$ sections. 
EFFECT OF ANNEALING ON HOT BAND TEXTURE
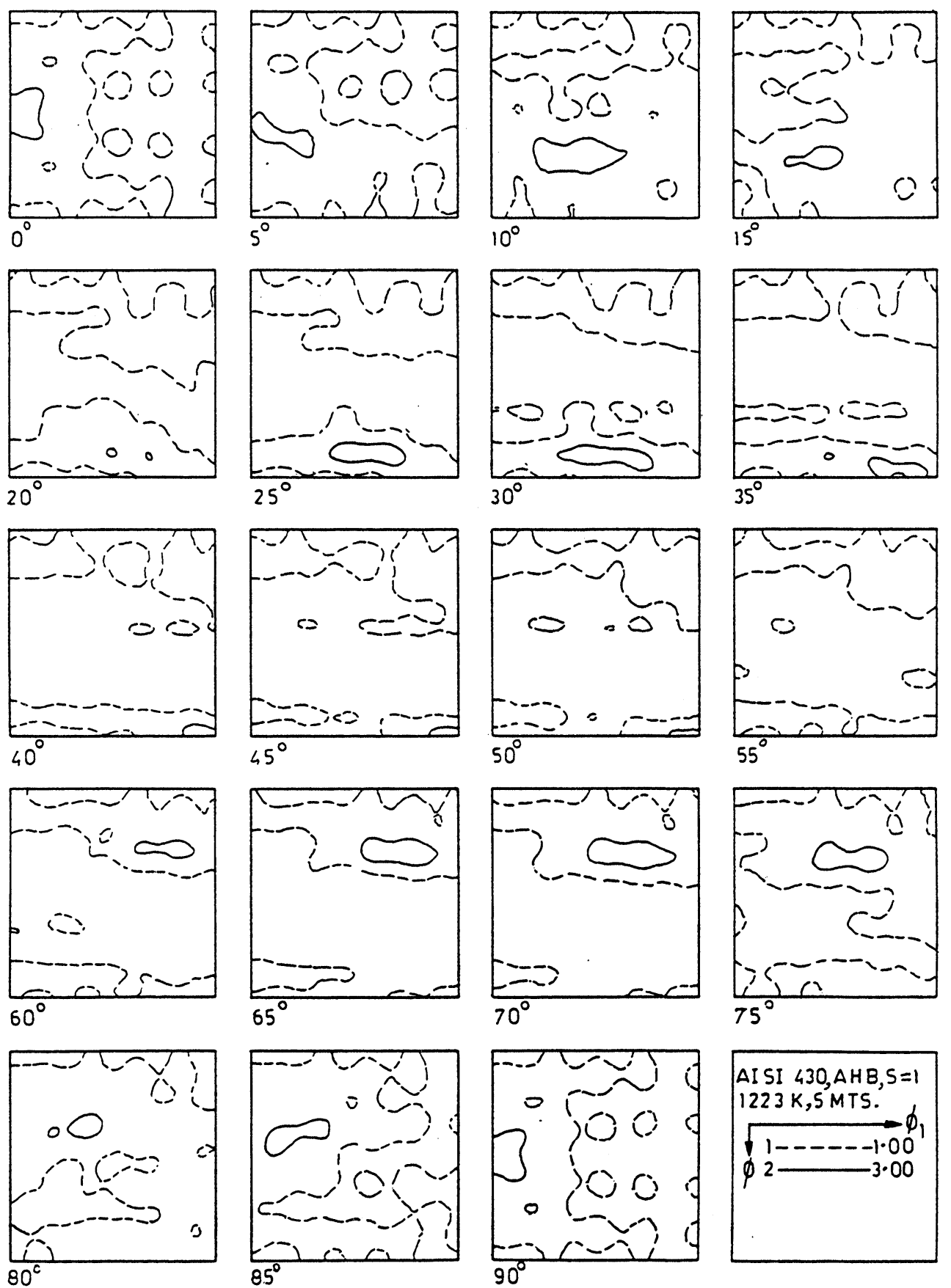

Figure 6 ODF for surface $(S=1)$ level of two-phase annealed hot band in constant $\phi_{2}$ sections. 


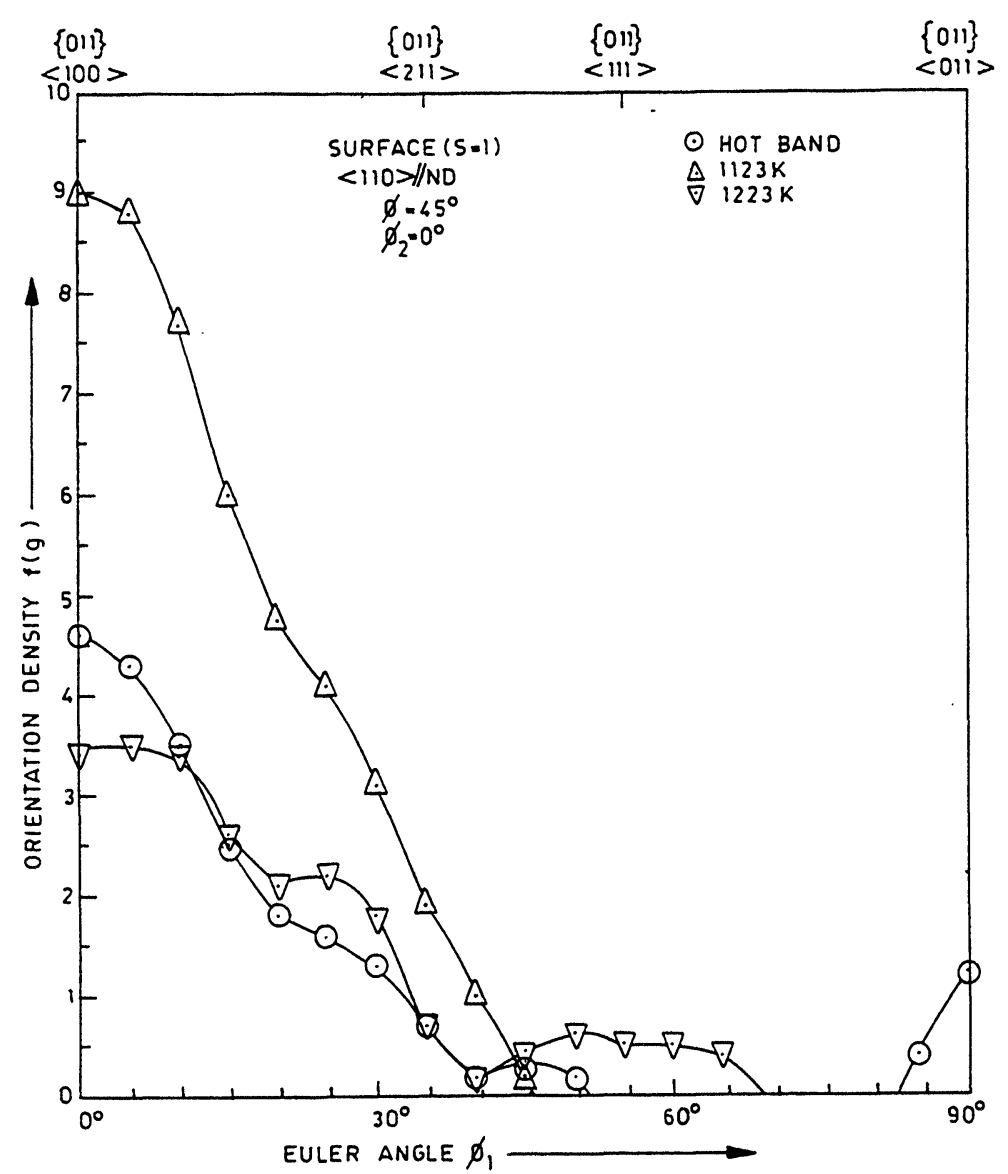

Figure 7 Orientation density plot along $<110>/$ NDD fibre present in the surface layer $(S=1)$.

It is interesting to note from the above mentioned ODF results that the texture distribution near the surface layer of the HB itself is nearly random, except for a fairly strong orientation density at $\{011\}<100>$. The single-phase annealing treatment has led to the sharpening, in the surface-layer, of all the components of the three limited orientation tubes and in particular, of the orientations $\{011\}<100>$, $\approx\{123\}<634>$ and $\{112\}<111>$ by increasing their orientation densities substantially. Further, the density of the texture component $\{001\}<100>$ belonging to $<100>/ / R D$ fibre has decreased considerably while that of $\{011\}<112>$ component has increased appreciably. In contrast, after two-phase annealing treatment, the orientation density, in the surface layer of the $\mathrm{HB}$, increases strongly at $\approx\{123\}<634>$ and $\{112\}<111\rangle$ and there is a decrease in the orientation density of $\{011\}<100>$ and $\{001\}<100>$. Furthermore, the increase in orientation density of RD rotated cube $\left\{\begin{array}{lll}0 & 3 & 11\end{array}\right\}<100>$ and of ND rotated component $\{011\}<113>$ occurs marginally.

On the other hand, the three dimensional orientation distribution functions (ODFs) of crystallites at the central layer $(S=0)$ of the $H B$, single-phase and two-phase 


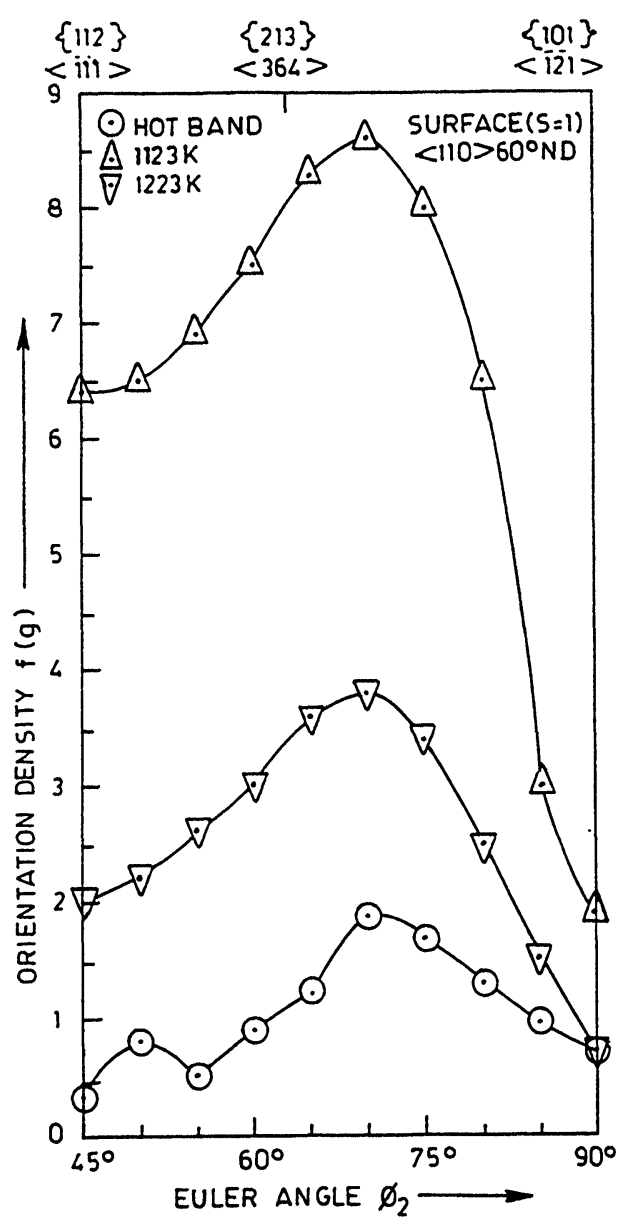

Figure 8 Orientation density plot along $<110>60^{\circ} \mathrm{ND}$ fibre present in the surface layer $(S=1)$.

annealed AHBs in constant $\phi_{1}$ sections through Euler space are given in Figures 10, 11 and 12, respectively. One recognises that, at first glance, the major orientations $\{001\}<110\rangle,\{001\}<100>$ and $\approx\{112\}<110>$ as well as the minor texture components $\approx\{111\}<112>$ and $\{011\}<100>$ are the special features of these ODFs results. Generally, the texture in the central layer can be best characterised by four partial or limited orientation tubes in the Eulerian space. The first orientation tube with its $\langle 110\rangle$ fibre axis parallel to $\mathrm{RD}(<110>/ / \mathrm{RD})$ lies in the $\phi_{1}=0^{\circ}$ section at $\phi_{2}=45^{\circ}$ along $\phi$ direction and runs from $\{001\}<110\rangle$ to near $\{112\}<110>$, while the second tube with its fibre axis $<110>$ inclined about $30^{\circ}$ from ND towards $\mathrm{RD}\left(<110>30^{\circ} \mathrm{ND}\right)$ extends between $\approx\{112\}<110>$ and $\approx\{111\}<112>$. The orientation $\approx\{112\}<110>$ is the joining point of $<110>/ / R D$ and $<110>30^{\circ} \mathrm{ND}$ fibres. The third orientation tube with $<001>$ fibre axis parallel to ND $(<001>/ / N D)$ stretches from $\{001\}<110>$ at $\phi_{1}=\phi=0^{\circ}$ and $\phi_{2}=45^{\circ}$ to $\{001\}<100>$ at $\phi_{1}=\phi=0^{\circ}$ and $\phi_{2}=0^{\circ}$ or $90^{\circ}$. The orientation $\{001\}<110>$ is the meeting point of $<110>/ / R D$ and $<001>/ / N D$ fibres. 


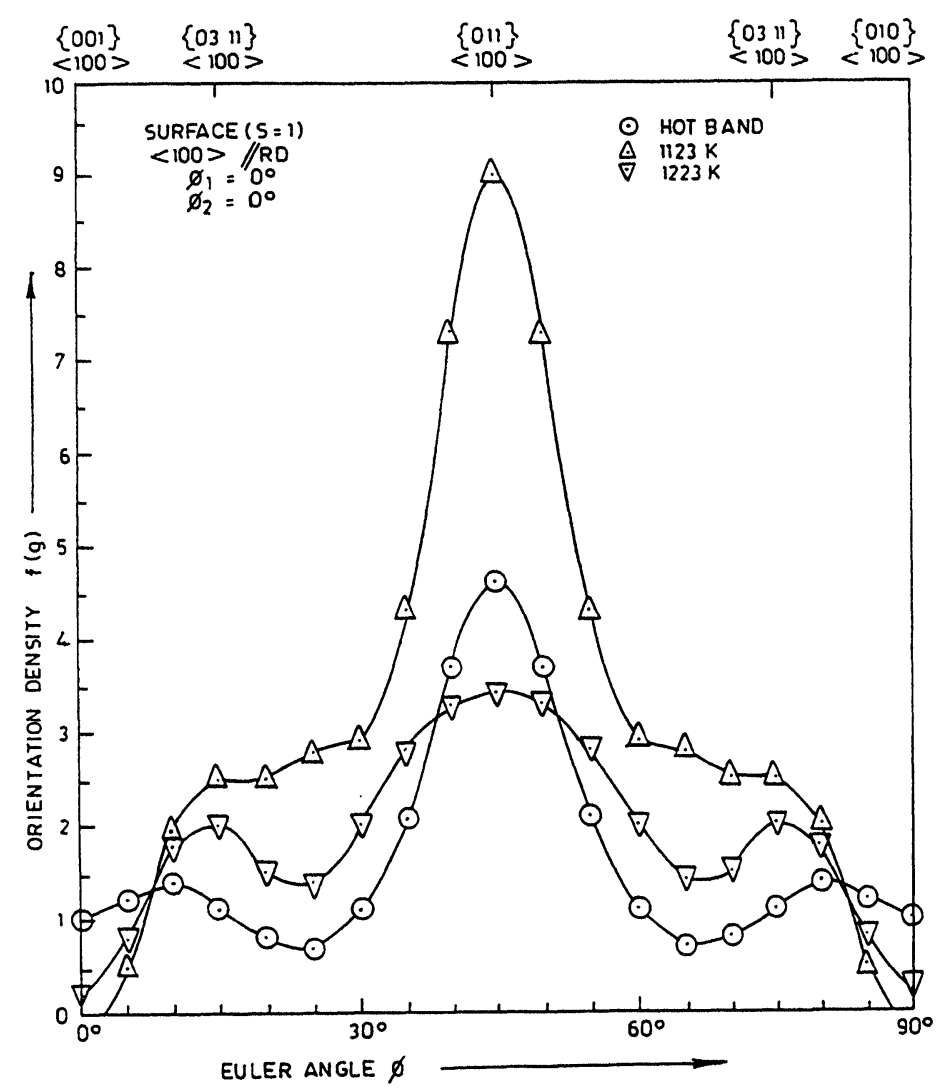

Figure 9 Orientation density plot along $<100>/ / R D$ fibre present in the surface layer $(S=1)$.

The fourth orientation tube is described by $<100>/ / R D$ fibre running from $\{001\}<100>$ at $\phi_{1}=\phi=\phi_{2}=0^{\circ}$ to $\{011\}<100>$ at $\phi_{1}=\phi_{2}=0^{\circ}$ and $\phi=45^{\circ}$. Here, the orientation $\{001\}<100>$ is the junction point of $<001>/ / N D$ and $<100>/ /$ RD fibres. However, these partial fibres reveal many important differences depending upon the materials. Some interesting and important information can be extracted from $\phi_{2}=45^{\circ}$ section of the above mentioned ODFs [Figure 13 (a), (b) and (c)] and accordingly Figures 14, 15, 16 and 17 show the orientation density plots along $<110>/ / R D,<110>30^{\circ} \mathrm{ND}$, $<001>/ / \mathrm{ND}$ and $<100>/ / \mathrm{RD}$ fibres. The texture index values determined at the central layer of the HB, single-phase and two-phase annealed AHBs are 32.41, 21.71 and 7.01, respectively.

It becomes clear from the ODF results [Figures 10 and 13 (a)] and also from the orientation density plots (Figures 14,15,16 and 17) that the texture at the central layer of the HB is characterised by $<110>/ / R D,<001>/ / N D$ and $<100>/ / R D$ fibres with a very strong orientation density at $\approx\{001\}<110>, \approx\{112\}<110>$ and $\{001\}<100>$. Here, the fibre $<110>30^{\circ} \mathrm{ND}$ is completely absent. However, the orientations $\approx\{111\}<112>$ and $\{011\}<100>$ are present as minor elements of the centre texture. This central layer, exhibits after single-phase annealing treatment, essentially the same features as in the $\mathrm{HB}$, although some orientations like $\approx\{001\}<110>$ and $\approx\{111\}<112>$ are 

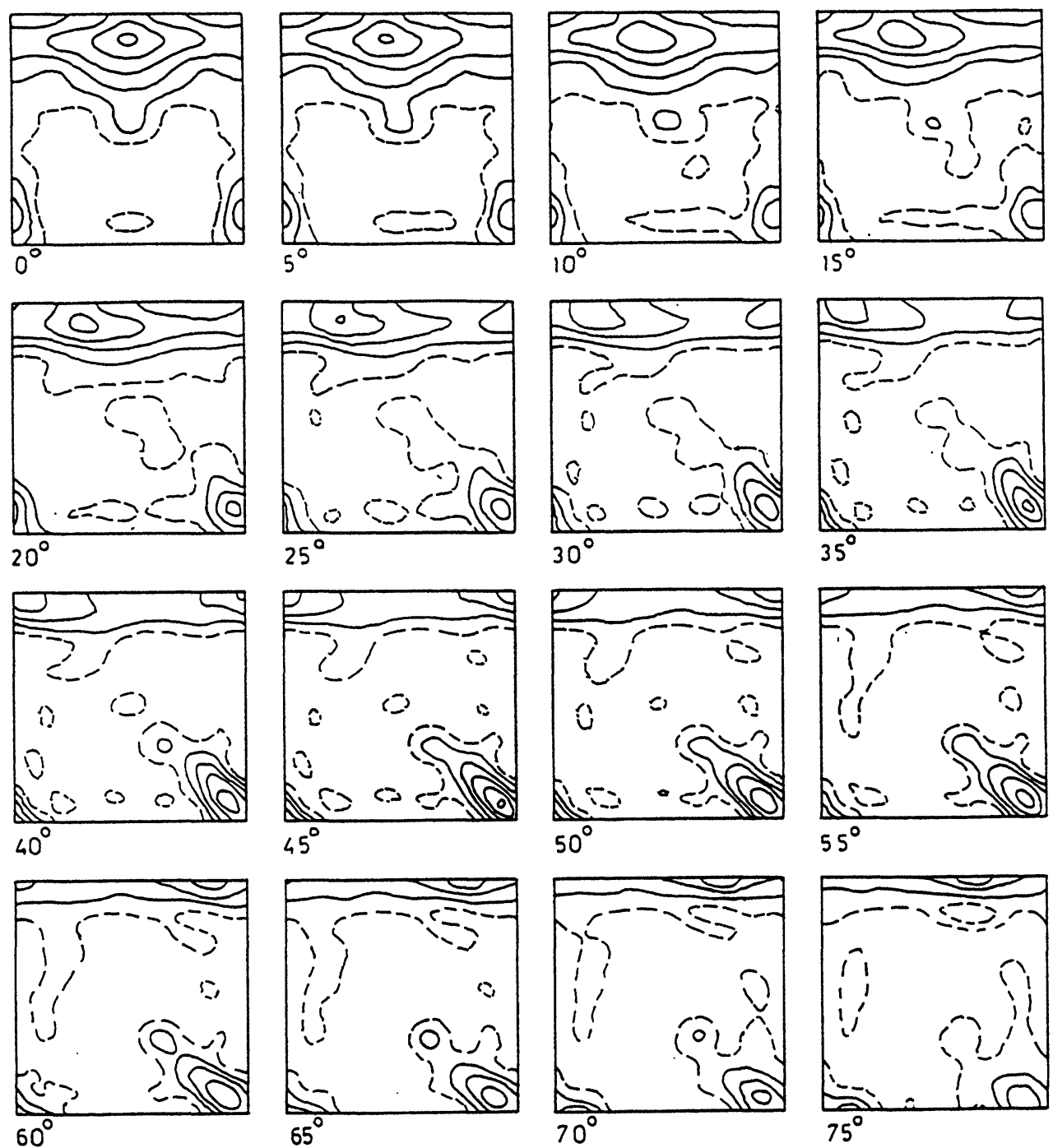

$$
55^{\circ}
$$
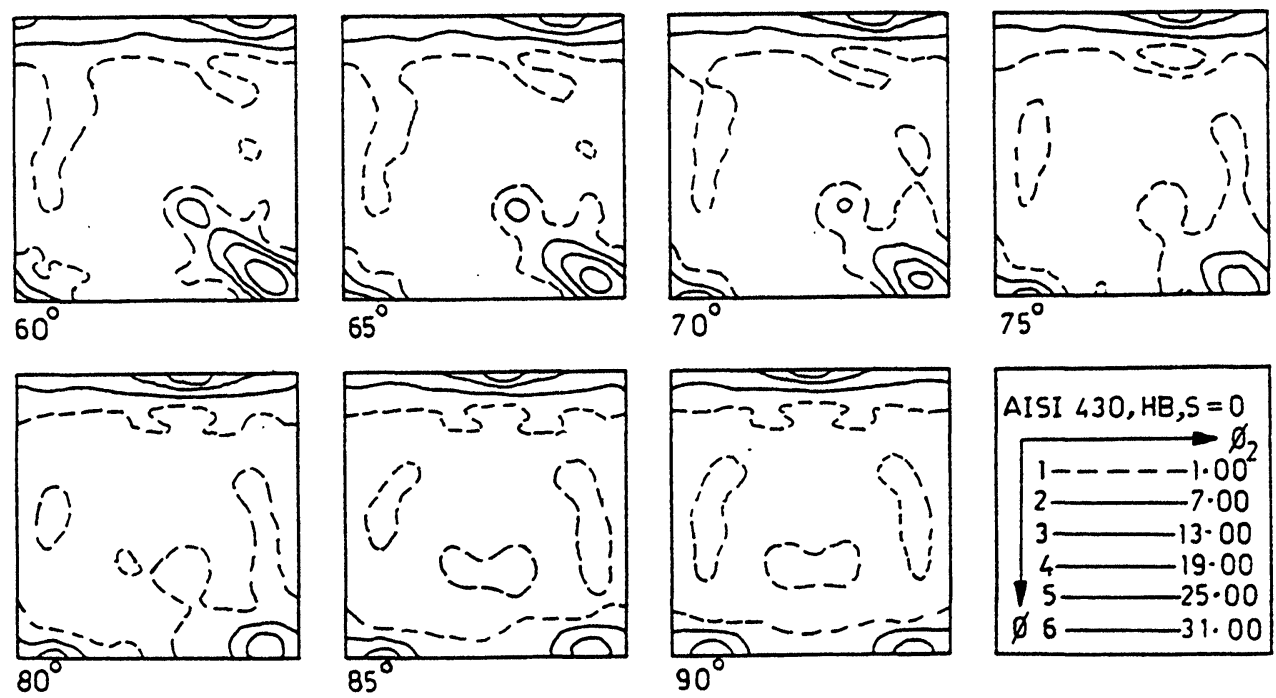

Figure 10 ODF for centre $(S=0)$ level of hot band in constant $\phi_{1}$ sections. 

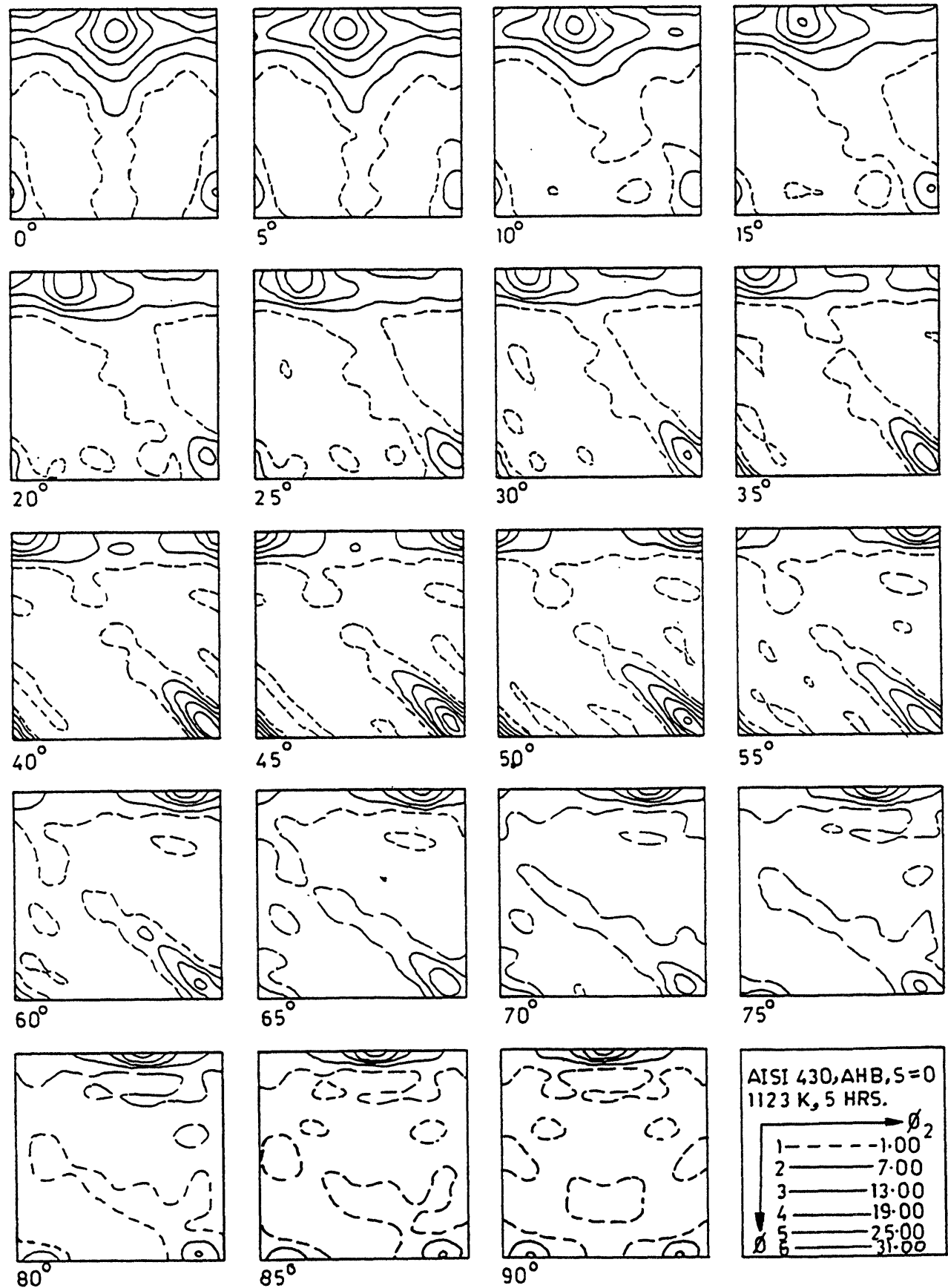

Figure 11 ODF for centre $(S=0)$ level of single-phase annealed hot band in constant $\phi_{1}$ sections. 

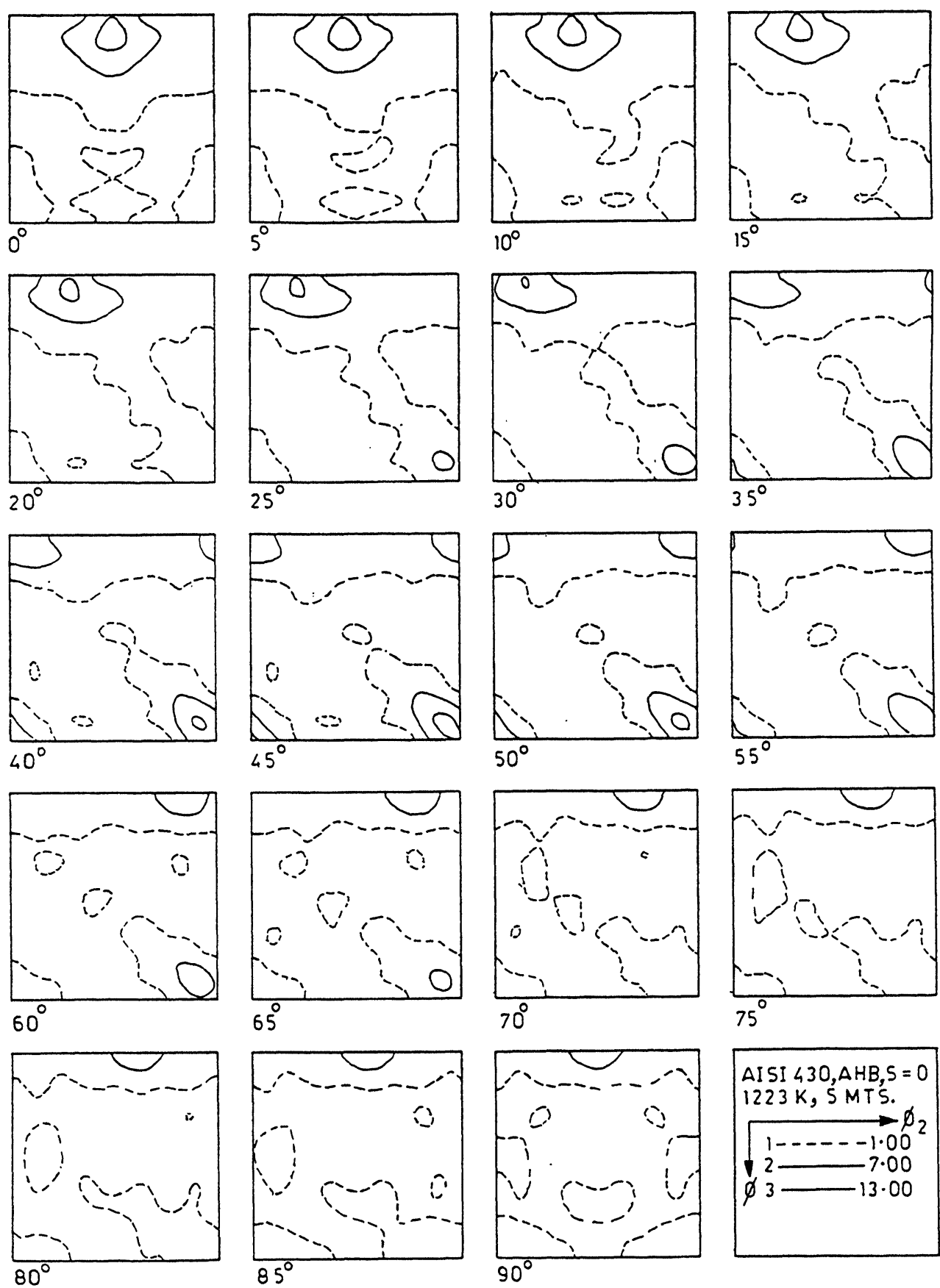

AISI $430, A H B, S=0$

$1223 \mathrm{~K}, 5$ MTS.

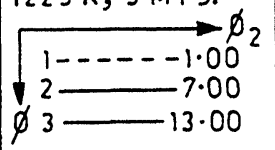

Figure 12 ODF for centre $(S=0)$ level of two-phase annealed hot band in constant $\phi_{1}$ sections. 
a)
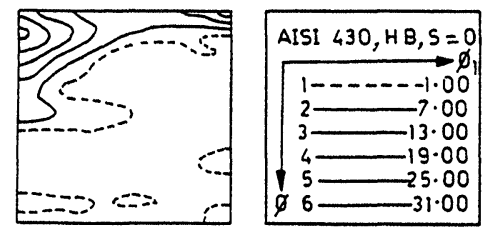

b)
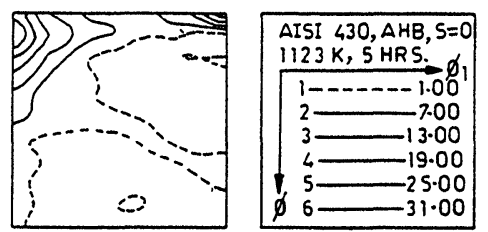

c)
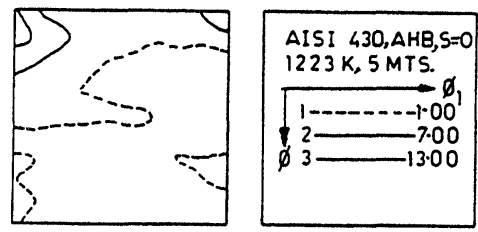

Figure 13 ODF for centre ( $S=0$ ) level in section $\phi_{2}=45^{\circ}$ : (a) hot band (b) single-phase annealed hot band (c) two-phase annealed hot band.

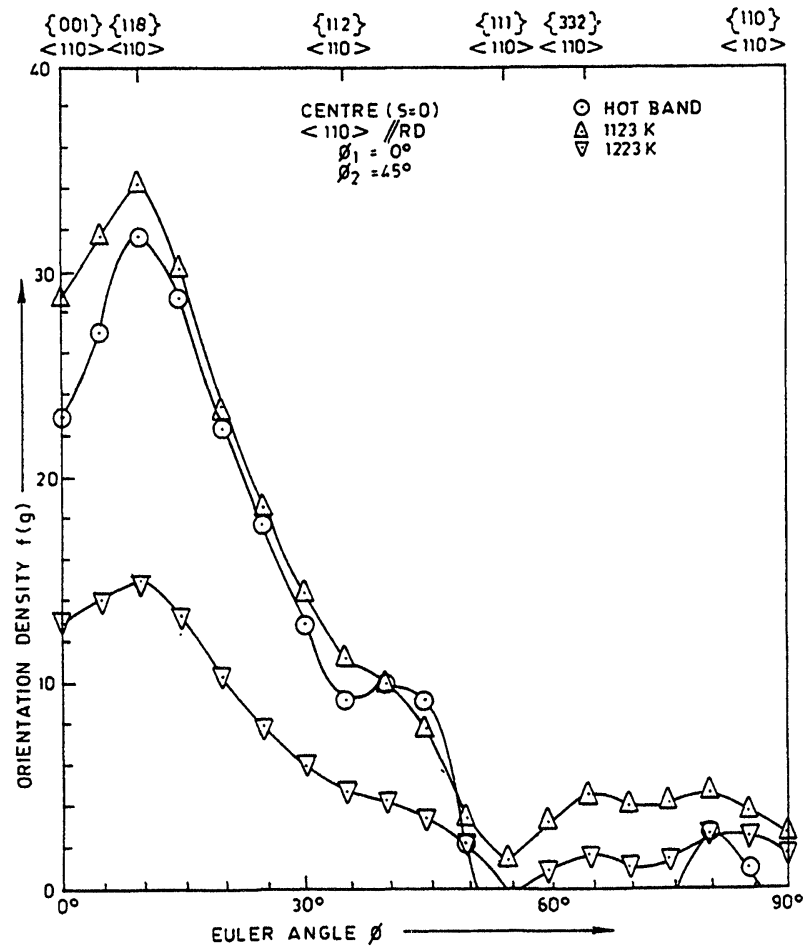

Figure 14 Orientation density plot along $<110>/ R D$ fibre present in the central layer $(S=0)$. 


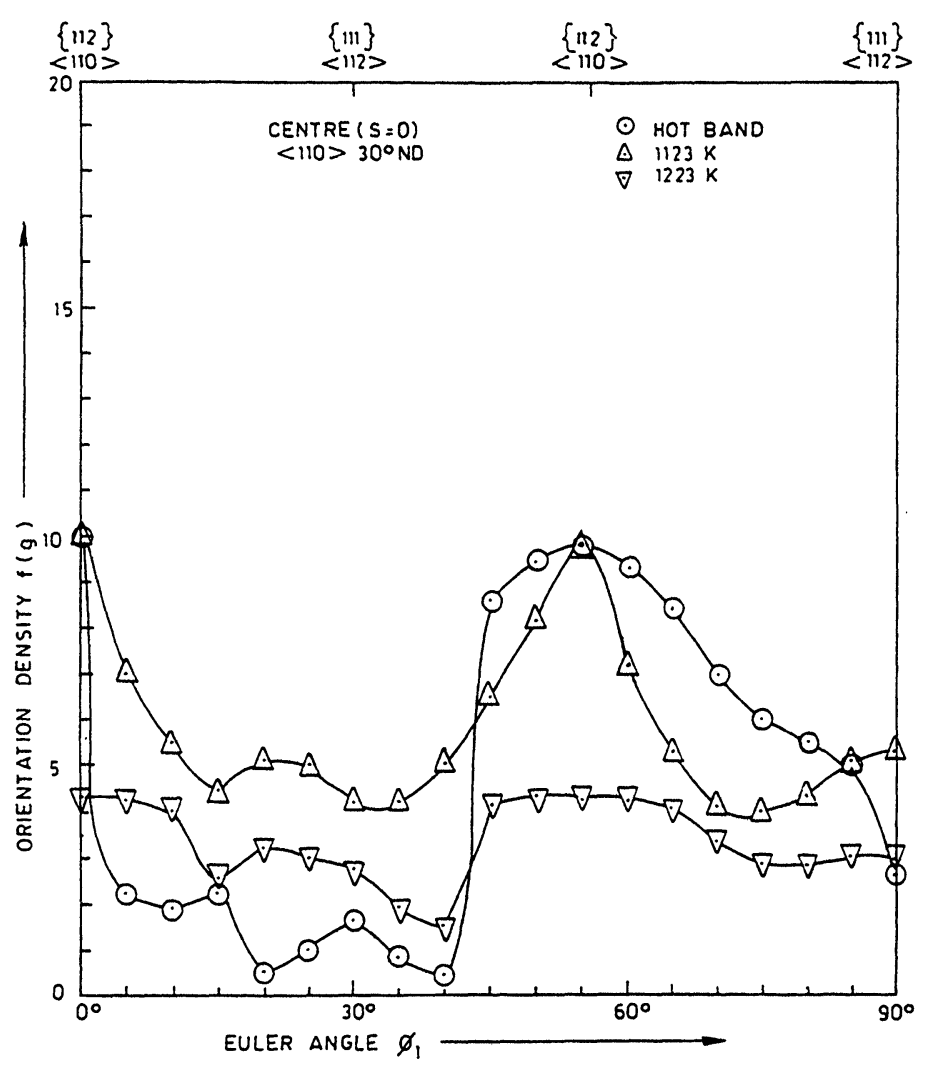

Figure 15 Orientation density plot along $<110>30^{\circ} \mathrm{ND}$ fibre present in the central layer $(S=0)$.

sharpened at the expense of the other texture components of the orientation fibres $<001>/ / \mathrm{ND}$ and $<100>/ / \mathrm{RD}$ and in particular of $\approx\{001\}<100>$ and $\{011\}<100>$. Furthermore, the $<110>30^{\circ} \mathrm{ND}$ fibre has appeared and the intensity of the texture components along this fibre, other than $\approx\{112\}<110>$, is enhanced. In contrast, the twophase annealing treatment has considerably decreased the strength of the texture components of all four limited orientation fibres and in particular, the fibres $<100>/ / \mathrm{RD}$ and $<110>30^{\circ} \mathrm{ND}$ disappear almost completely. However, the other two fibres $<110>/ / R D$ and $<001>/ / N D$, still, persist [Figure 13(c)] but with strongly reduced intensities and the orientation $\{001\}<110>$ remains as the major texture component at the central layer, after this annealing treatment.

\section{DISCUSSION}

\subsection{Evolution of Hot Band Texture}

During hot rolling, the surface and sub-surface layers undergo a shear strain deformation, while the central layers are subjected to plain strain deformation. Accordingly one obtains shear or rolling textures in deformed materials. Since the 


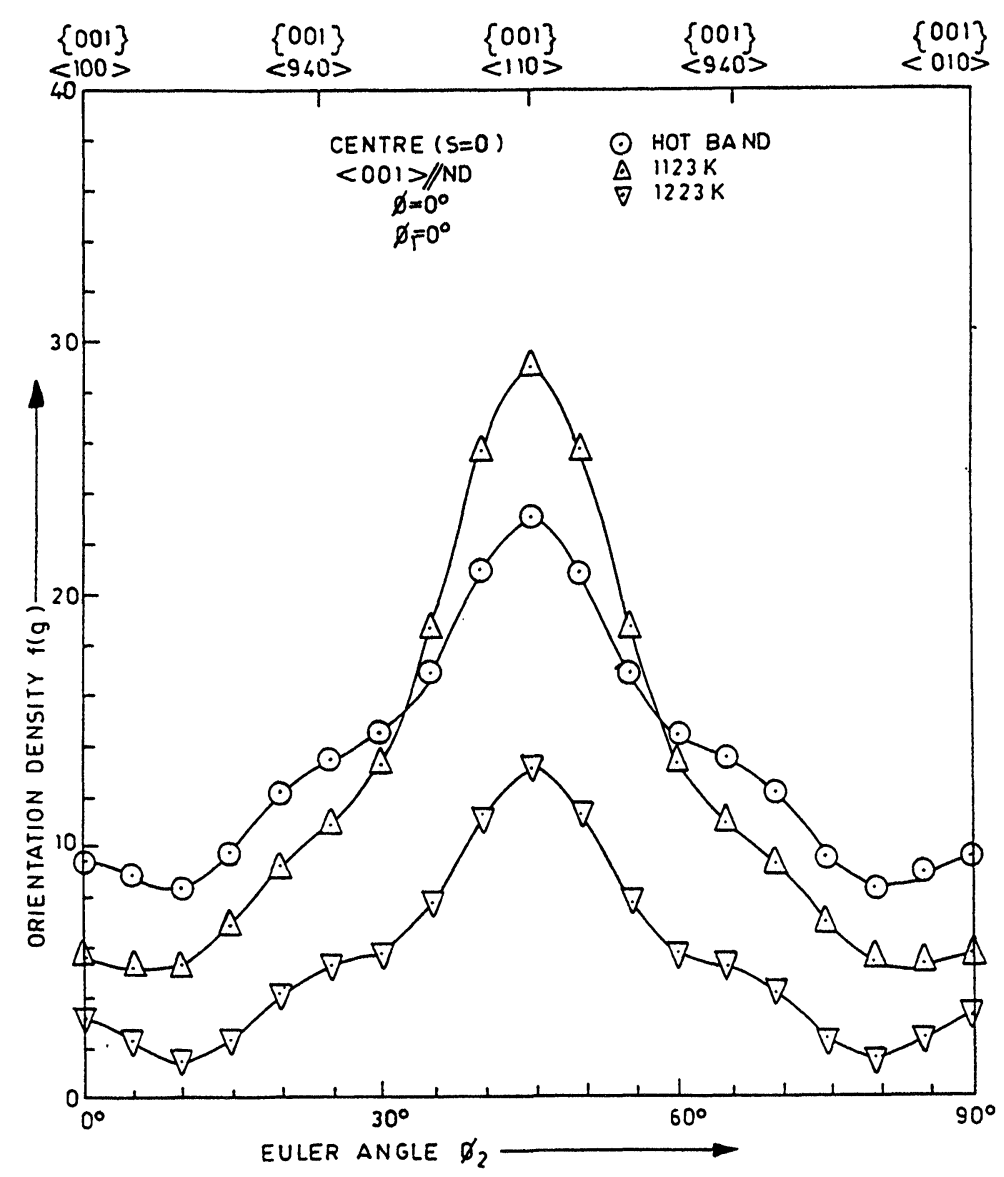

Figure 16 Orientation density plot along $<001>/$ ND fibre present in the central layer $(S=0)$.

surface layers experience, because of water spraying and contact with the roll surface, a comparatively lower temperature than the central layers, dislocation density is higher in the surface layers. In the hot strip mill, the deformation is carried out in more number of steps and the last few steps determine, to a great extent, the textural and microstructural state of grains through the thickness of the strip. The deformation temperature plays also an important role by invoking the dynamic recrystallisation followed by the post-dynamic recrystallisation in the inter pass intervals (Samuel et al., 1988). In case of $17 \% \mathrm{Cr}$ ferritic stainless steel, continuously cast slabs are hot rolled to strips in the two-phase $(\alpha+\gamma)$ region, where ferrite and austenite grains are deformed according to their own crystal plasticity. As the surface temperature is lowere $\gamma$ than that at centre, less dynamic recovery and higher stored deformation energy initiate more dynamic recrystallisation in the surface and sub-surface layers than in the central layers, during the last few passes. Furthermore, the partial transformation $\gamma \rightarrow \alpha$ before the onset of martensite formation and carbide precipitation in ferrite may occur with the fall in the hot strip temperature. 


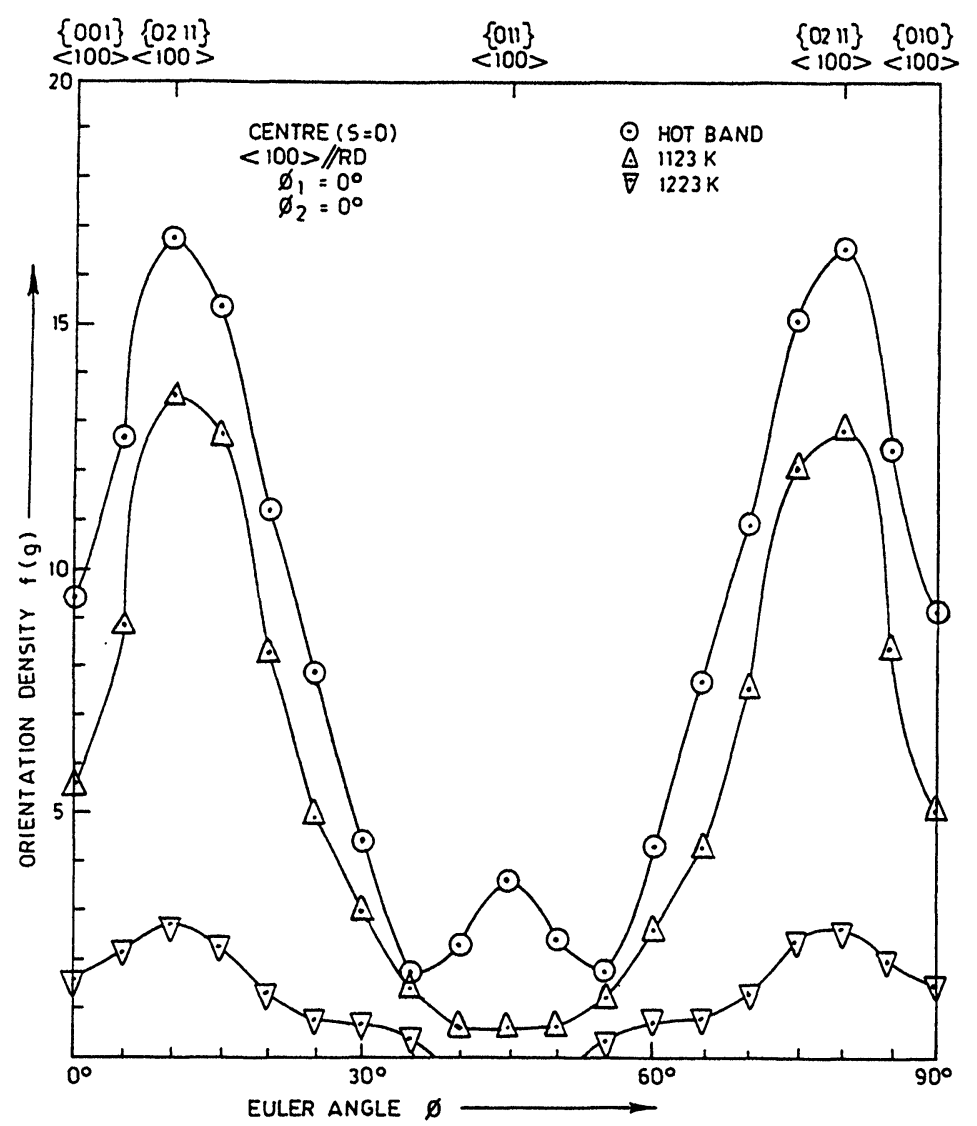

Figure 17 Orientation density plot along $<100>/ / R D$ fibre present in the central layer $(S=0)$.

In view of the above physical processes (i.e. hot deformation, recrystallisation, partial ferrite and martensite formation as well as carbide precipitation), it can be inferred that the presence of banded structure of ferrite and martensite (the martensite forms, as a result of partial transformation $\gamma \rightarrow \alpha^{\prime}$ upon cooling from hot rolling) through the thickness of the HB [Figure 1 (a) and (b)] is the consequence of hot rolling in the two-phase $(\alpha+\gamma)$ region, in the temperature range $1453 \mathrm{~K}$ to $1223 \mathrm{~K}$, where both ferrite and austenite are stable. The origin of such a banded distribution of structures seems to be associated with the dendritic structure of the continuously cast slabs, where some alloying elements such as $\mathrm{Cr}, \mathrm{C}$ and $\mathrm{N}$ seggregate (Defilippi and Chao, 1971). The regions which are lean in $\mathrm{Cr}$ and rich in $\mathrm{C}$ and $\mathrm{N}$ transform to austenite $(\gamma)$ during hot rolling. The ferrite band boundaries are the most potential sites for nucleation of this austenite and an optimum amount $(\approx 30 \%)$ of austenite forms at a temperature about $1353 \mathrm{~K}$. Since the hot rolling temperature and the total deformation are high, most of the ferrite and the austenite bands, both in the surface and the central layers, are dynamically recrystallised [Figure 1(a) and (b)]. The presence of comparatively coarse ferrite bands in the $\mathrm{HB}$ indicates that its recrystallisation is 
sluggish due to the precipitation of carbides which delays the dynamic recrystallisation process. Furthermore, the formation of very fine ferrite grains within the martensite (i.e. prior austenite) regions suggests that nucleation of transformation-induced ferrite (austenite-derived ferrite) is also occurring upon cooling from hot rolling but before the onset of martensitic transformation.

The presence of the texture components $\{011\}<100>$ and $\{011\}<113>$ along the partial fibre $<110>/$ ND with the former as the major element and the appearance of $\approx\{123\}<634>,\{112\}<111>$ and $\{011\}<112>$ along the limited fibre $<110>60^{\circ} \mathrm{ND}$ with the latter two components as the minor ones, in the surface layer of the HB (Figure 4), suggest that these texture components are essentially the elements of shear texture and formed by the simultaneous action of shear deformation, due to the frictional force between the strip surface and the working rolls, and dynamic recrystallisation occurring by sub grain growth process, which leads to elongated ferrite grains [Figure 1(a)]. In fact, the orientation $\{011\}<100\rangle,\{011\}<112\rangle$ and $\left\{\begin{array}{lll}4 & 4 & 11\end{array}\right\}<11 \quad 11 \quad 8>$ are the ones predicted theoretically as the stable orientations by Dillamore and Katoh (1974a) under the action of imposed shear. Since these stable orientations and the spread range between them (i.e. $<110>/ / \mathrm{ND}$ and $<110>60^{\circ} \mathrm{ND}$ fibres) belong to the regions of uniform orientations where slip rotations, usually, converge, they are best suited for the formation of recrystallised nuclei by sub grain growth and also by grain boundary nucleation (Dillamore and Katoh, 1974b). Further, it is important to note that the martensitic transformation of austenite grains, in the surface layer of the $\mathrm{HB}$ following hot rolling, also contributes to these shear texture components. These austenite grains possess the orientations of shear texture, during hot rolling, and get dynamically recrystallised by the sub grain growth process (Singh, Ramaswamy and Suryanarayana, 1991). These austenite shear texture components are mainly distributed along $<110>/ / \mathrm{RD}$ and $<110>30^{\circ} \mathrm{ND}$ fibres with $\approx\{112\}<110>$, $\approx\{111\}<110>, \approx\{001\}<110>$ as major and $\approx\{111\}<112>$ and $\approx\{111\}<113>$ as minor elements. The components of predicted transformation texture of martensite from austenite shear orientations, using Kurdjumov-Sachs orientation relationship without variant selection, are mainly $\{011\}<100\rangle, \approx\{112\}<111\rangle, \approx\{123\}<634\rangle,\{011\}<112\rangle$ and $\{001\}<100>$ (Singh, 1989). The latter two orientation elements are the minor components. Thus it can be concluded that the surface texture components as major elements $\{011\}<100>, \quad\{011\}<113>$ and $\approx\{123\}<634>$ and as minor elements $\{112\}<111>,\{011\}<112>$ and $\{001\}<100>$ belonging to the partial fibres $<110>/ / N D$, $<110>60^{\circ} \mathrm{ND}$ and $<100>/ / \mathrm{RD}$ are, in fact, formed by the simultaneous action of shear deformation and dynamic recrystallisation of ferrite and austenite grains, during hot rolling, by sub grain growth and grain boundary nucleation processes and also by the martensitic transformation of austenite grains during cooling from hot rolling. However, these processes give rise to a nearly random texture $(J=1.56)$ in the surface layer of the HB.

On the contrary, the central layer of the HB reveals the presence of very strong texture components $\approx\{001\}<110>$ and $\approx\{112\}<110>$ along $<110>/ /$ RD fibre, the complete absence of $<110>30^{\circ} \mathrm{ND}$ fibre except the component $\approx\{111\}<112>$ as the minor element and the existence of strong component $\{001\}<100>$ along $<001>/$ ND and $<100>/ / R D$ fibres and also of the minor component $\{011\}<100>$ along $<100>/$ /RD fibre [Figures 10 and 13(a)] and thus possesses a strong recrystallisationtype hot rolling texture $(\mathrm{J}=32.41)$. According to Dillamore and Katoh $(1974 \mathrm{a}$ and b), in B.C.C. metals the most stable orientation $\{112\}<110\rangle$ and the quite stable orientations $\{001\}<110>$ and $\left\{\begin{array}{llll}11 & 11 & 8\end{array}\right\}<4 \quad 411>$, the latter one is nearer to $\{111\}<112>$, 
are best suited for recrystallisation by sub grain growth and grain boundary nucleation processes. Since most of the ferrite grains are in the form of elongated bands [Figure 1(b)], it becomes apparent that they are dynamically recrystallised by the process of sub grain growth, though grain boundary nucleation and growth also occur in some grains and remain confined within the bands. This confinement of the growth is mainly due to the pinning action of $\mathrm{M}_{23} \mathrm{C}_{6}$ carbides which precipitate mostly on the $\alpha-\alpha$ and $\alpha-\gamma$ boundaries, and also due to the presence of prior austenite bands on ferrite band boundaries. The predominance of $\approx\{001\}<110>$ component, over other elements of the centre texture, seems to be inherited from the orientations $\{001\}<U V W>$ of the dendritic grains of the cast slabs (Littman, 1975; Shimizu, Ito and Iida, 1986). Part of the contribution to these ferrite texture components is through the inheritance of austenite orientations, particularly of the components $\{001\}<100>$ and $\{011\}<112>$, where grains of austenite transform to martensite (Singh, 1989). Hence, it becomes clearly evident from the microstructural and the textural evidences [Figures 1(b) and $10]$ that the banded distribution of ferrite and martensite, having $\approx\{001\}<110>$, $\approx\{112\}<110>$ and $\approx\{001\}<100>$ orientations as major and $\approx\{111\}<112>$ and $\{011\}<100>$ as minor components, are the result of the combined effect of plain strain deformation and dynamic recrystallisation by sub grain growth and grain boundary nucleation processes in ferrite bands and the martensitic transformation of austenite grains during cooling from the hot rolling. However, the formation of the orientation $\{011\}<100\rangle$ can be attributed to the transition band nucleation in the grains of $\{111\}<112>$ orientation (Hu, 1969).

\subsection{Evolution of Single-Phase Annealing Texture}

During single-phase $(\alpha)$ annealing of the $\mathrm{HB}$, the decomposition of martensite $\left(\alpha^{\prime}\right)$ bands into aggregates of ferrite and carbide (presumably $\mathrm{M}_{23} \mathrm{C}_{6}$ ), and the precipitation of carbides within ferrite grains occur [Figure 2(a) and (b)]. The most preferred sites for this precipitation are the prior $\alpha-\gamma$ and the $\alpha-\alpha$ boundaries. However, some ferrite grains grow through the ferrite bands and the decomposed martensite bands by the migration of the boundaries of the ferrite nucleated at the above mentioned boundaries. Since, the bands of ferrite and martensite (prior austenite) are in the form of elongated shape, preferred precipitation of carbides along the prior $\alpha-\gamma$ and the $\alpha-\alpha$ boundaries produces through-thickness sheets of carbides laying parallel to the rolling plane of the HB strip and these sheets hinder the formation of complete polygonal ferrite grains and thus they lead to the persistence of microstructural banding.

The strong sharpening, in the surface layer, of the partial orientation fibres $<110>/$ ND and $<110>60^{\circ} \mathrm{ND}$ and in particular of the shear texture components $\{011\}<100>, \approx\{123\}<634>$ and $\{112\}<111>$ (Figure 5) at the expense of $\{001\}<100>$ and other random orientations, as well as the increase in the texture sharpness $(\mathrm{J}=5.10)$, indicate that during single-phase annealing treatment, ferrite grains having orientations on the $<110>/ / \mathrm{ND}$ fibre and also on $<110>60^{\circ} \mathrm{ND}$ fibre are growing by consuming small grains of random orientations through the process of normal grain growth. The same situation prevails with the very mild sharpening of the orientation elements $\{011\}<112>$ and $\left\{\begin{array}{lll}0 & 3 & 11\end{array}\right\}<100>$. It is quite possible that the austenitederived ferrite, having a size advantage over the martensite decomposed ferrite, plays a dominant role in strengthening the orientation elements $(\{011\}<100>, \approx\{123\}<634>$ and $\{112\}<111>$ ) of the shear texture. These austenite-derived ferrite grains grow, through the process of epitaxial growth, at the cost of the martensite-derived ferrite grains. 
On the contrary, the central layer exhibits, after single-phase annealing, essentially the same features of the texture [Figures 11 and 13 (b)], as that present in the HB [Figures 10 and 13(a)], although the texture component $\approx\{001\}<110>$ of $<110>/ / R D$ fibre and other orientation elements of $<110>30^{\circ} \mathrm{ND}$ fibre except $\approx\{112\}<110>$, are sharpened. This enhancement in the strength of the texture components occurs at the cost of the orientations of $<100>/ / R D$ fibre and in particular of $\approx\{001\}<100>$ and $\{011\}<100\rangle$ through the process of normal grain growth of ferrite. Further, the comparatively lower value of the texture index $(J=21.71)$ reveals that some ferrite grains of random orientations have been produced by this annealing treatment. The origin of these random ferrite grains seems to be associated with the martensite-derived ferrite, obtained as a result of martensite decomposition into ferrite+carbide aggregate, and also with the precipitation of comparatively finer carbides at the prior $\alpha-\gamma$ and $\alpha-\alpha$ boundaries, which hinders the epitaxial growth of the austenite-derived ferrite grains.

\subsection{Evolution of Two-Phase Annealing Texture}

In contrast to single-phase annealing treatment, the two-phase annealing has resulted in the formation of ferrite+carbide aggregates, just decomposed from the martensite bands, the grain growth of the ferrite grains, derived from austenite and also nucleated at the prior $\alpha-\gamma$ boundaries, and the auto-tempering of the grain boundary martensite into ferrite+carbide aggregates, obtained as a result of two-phase annealing and air cooling [Figure 3(a) and (b)]. In addition to the above microstructural features, the precipitation of $\mathrm{M}_{23} \mathrm{C}_{6}$ carbides within the ferrite grains and at the $\alpha-\alpha$ and the prior $\alpha-\gamma$ boundaries and also the formation of some ferrite from the two-phase austenite have occurred, through the thickness of the HB. In other words, the physical processes occurring, during and after this two-phase annealing of the $\mathrm{HB}$, having the microstructural features as $\alpha+\alpha^{\prime}+\mathrm{M}_{23} \mathrm{C}_{6}$, can be generalised as follows:

1) decomposition of $\alpha^{\prime}$ into $\alpha+\mathrm{M}_{23} \mathrm{C}_{6}$ and dissolution of some prior $\mathrm{M}_{23} \mathrm{C}_{6}$

2) growth of grains of untransformed $\alpha$ and austenite-derived $\alpha$

3) partial transformation of $\alpha$ into $\gamma$

4) transformation of ferrite-derived $\gamma$ into $\alpha$ and then to $\alpha^{\prime}$

5) Precipitation of $\mathrm{M}_{23} \mathrm{C}_{6}$ within ferrite and auto-tempering of the two-phase austenitederived $\alpha^{\prime}$ into $\alpha+\mathrm{M}_{23} \mathrm{C}_{6}$

While the first three processes occur simultaneously and concurrently during annealing, the latter processes become effective only after annealing. Because of the occurrence of the above phase transformation processes, the microstructural banding is destroyed to some extent.

It is clear from the ODF result (Figure 6) of the surface texture of the HB, after two-phase annealing, that there is a mild sharpening of the shear texture components $\approx\{123\}<634>$ and $\{112\}<111>$ on the partial fibre $<110>60^{\circ} \mathrm{ND}$ as well as of $\{011\}<113>$ and $\left\{\begin{array}{lll}0 & 3 & 11\end{array}\right\}<100>$ on the $<110>/$ ND and $<100>/ / R D$ fibres, respectively. This mild sharpening of the texture is also corroborated by the slightly higher texture index $(\mathrm{J}=1.83)$ which shows the existence of, still, nearly random texture in the surface layer. It is apparent from this mild sharpening that the austenite-derived 
ferrite grains, having orientation $\approx\{123\}<634>,\{112\}<111>,\{011\}<113>$ and $\{03$ $11\}<100>$, grow by consuming some grains of the martensite-derived ferrite, which are smaller in size, during this high temperature two-phase quick annealing. Furthermore, the partial transformation sequence $\alpha \rightarrow \gamma \rightarrow \alpha+\alpha^{\prime}$ maintains predominantly the status-quo of the surface texture of the HB, which is nearly random.

On the contrary, the two-phase treatment has considerably weakened, in the central layer, the strength of the texture components of the limited fibres $<110>/ / R D$, $<110>30^{\circ} \mathrm{ND}, \quad<001>/ \mathrm{ND}$ and $<100>/ / \mathrm{RD}$ and in particular of the orientations $\approx\{001\}<110\rangle, \approx\{112\}<110>$ and $\approx\{001\}<100>$ [Figures 12 and 13(c)]. By this treatment, the partial fibres $<110>30^{\circ} \mathrm{ND}$ and $<100>/ / \mathrm{RD}$, disappear in the central layer. Additionally, the very large decrease of texture index $(J=7.01)$ indicates that the textural banding (i.e. inhomogeneity), present in the central layer of the HB, is eliminated to a great extent. This weakening of the textural banding is the result of two-phase annealing, where the phase transformation sequence $\alpha \rightarrow \gamma \rightarrow \alpha+\alpha^{\prime}$ without variant selection becomes operative during and after annealing.

\section{CONCLUSIONS}

i) A through-thickness banding of ferrite and martensite exists in the hot band and the bands of ferrite get dynamically recrystallised by the process of sub grain growth of ferrite and grain boundary nucleated ferrite.

ii) The texture, at the surface of the hot band, is nearly random and characterised by a fairly strong shear texture component $\{011\}<100>$ on $<110>/$ NDD fibre in addition to a fairly sharp orientation element $\approx\{123\}<634>$ on $<110>60^{\circ} \mathrm{ND}$ fibre and $<100>/ / R D$ fibre. The orientation elements of these fibres are formed, during hot rolling in the two-phase region, at the surface, by the simultaneous action of shear deformation and dynamic recrystallisation as well as by the martensitic transformation of the remaining austenite during cooling. In the central layers of the hot band a very strong recrystallisation texture mainly described by $<110>/ / \mathrm{RD},<001>/ / \mathrm{ND}$ and $<100>/ / \mathrm{RD}$ fibres has been observed.

iii) The single-phase annealing treatment has led to the sharpening, in the surface layers, of three shear texture fibres and in particular of the components $\{011\}<100>\approx\{112\}<634>,\{112\}<111>$ and $\approx\{011\}<112>$. The central layer exhibits, after single-phase annealing, essentially the same features as in the hot band, although the orientation $\approx\{001\}<110>$ and the fibre $<110>30^{\circ} \mathrm{ND}$ are sharpened.

iv) The two-phase annealing has resulted in slight sharpening, in the surface layer, of shear texture components $\approx\{123\}<634>$ and $\{112\}<111>$ on $<110>60^{\circ} \mathrm{ND}$ fibre and weakened considerably, in the central layer, the textural banding and particularly the strength of $<110>/ / \mathrm{RD},<001>/ / \mathrm{ND},<100>/ / \mathrm{RD}$ and $<110>30^{\circ} \mathrm{ND}$ fibres.

\section{Acknowledgements}

The author would like to express his gratitude to the management of RDCIS, SAIL, Ranchi for according the permission to publish this work. 


\section{References}

Bunge, H. J. (1982). Texture Analysis in Materials Science, Butter Worths, London.

Chalk, P. L. (1969). U.S. Patent No. 2, 055, 461.

Chao, H. C. (1967). Trans. ASM., 60, 37.

Davison, R. M. (1974). Metall. Trans., 5A, 2287.

Davison, R. M. (1975). Metall. Trans., 6A, 2243.

Defilippi, J. D. and Chao, H. C. (1971). Metall. Trans., 2, 3209.

Dillamore, I. L. and Katoh, H. (1974a). Metal Sci., 8, -21.

Dillamore, I. L. and Katoh, H. (1974b). Metal Sci., 8, 73.

Harase, J., Heno, I. and Nagaie, T. (1983). Trans. ISIJ., 23, S625.

Harase, J., Kamano, Y. and Ueno, I. (1983). Trans. ISIJ., 23, S626.

Harase, J., Ohta, K., Takeshita, T. and Shimizu, R. (1990). Materials Forum, 14, 296.

Hölscher, M., Raabe, D. and Lücke, K. (1991). Steel Res., No. 12, 62, 567.

Hölscher, M. and Staubwasser, L. (1993). Innovation Stainless Steel, Florence, Italy, 239.

$\mathrm{Hu}$, H. (1969). Proc. Int. Conf. on "Texture in Research and Practice", Eds. J. Grewen and G. Wassermann, Springer Verlag, Berlin, 200.

Itoh, Y., Okajama, K., Maede, H. and Tashiro, K. (1982). Trans. ISIJ., 22, 223.

Kern, R. and Bergmann, H. W. (1978). Proc. ICOTOM 5, Vol. 1, Eds. G. Gottstein and K. Lücke, Springer Verlag, Berlin, 139.

Lewis, D. B. and Pickering, F.B. (1983). Metals Tech., 10, 264.

Littmann, M. F. (1975). Metall. Trans., 6A, 1041.

Lücke, K., Pospiech, J., Virnich, K. H. and Jura, J. (1981). Acta Met., 29, 167.

Matthies, S. (1979). Phys. Stat. Sol., (b) 92, P.K. 135.

Raabe, D. and Lücke, K. (1992). Scrip. Met. Mat., 26, 1221.

Samuel, F.H., Barbosa, R., Boratto, F., Yue, S. and Jonas, J.J. (1988). Proc. Int. Conf. on "Physical Metallurgy of Thermo-mechanical Processing of Steels and other Metals", Vol. 2, The Iron and Steel Institute of Japan, Tokyo, 721.

Sawatani, T., Ishii, M., Yoshimura, H. and Harase, J. (1985). U.S. patent No. 4, 515, 644.

Schulz, L. G. (1949). J. Appl. Phys., 20, 1030.

Shimizu, Y., Ito, Y. and Iida, Y. (1986). Metall. Trans., 17A, 1323.

Singh, C. D. (1989). Ph. D. Thesis, Banaras Hindu University, India.

Singh, C. D., Ramaswamy, V. and Suryanarayana, C. (1991). Textures and Microstructures, $13,227$.

Takechi, H., Kato, H., Sunami, T. and Nakayama, T. (1967). Trans. Jap. Inst. Metals, 8, 233.

Tashiro, K., Ikehara, Y., Yanai, T. and Matsumara, S. (1982). Trans. ISIJ., 22, 255.

Viallon, P. and Heretier, J. (1977). Centre de Research Bulletin, Creusot-Loire, 231.

Vlad, C. M., Dahms, M., Bunge, H. J. and Haase, M. (1988). Proc. ICOTOM 8, Eds. J. S. Kallend and G. Gottstein, The Metallurgical Society, AIME, Warrendale, 873.

Waxweiler, J. H. (1962). Canada Patent No. 697, 689.

Wright, R.N. (1972). Metall. Trans., 3A, 83.

Yamada, M. and Tokunaga, Y. (1985). Trans. ISIJ., 25, S 460. 